\title{
Promoting the "Child-Centred Approach" Through an E-Learning Training Course. Problems and Prospects
}

\author{
Caterina Bembich ${ }^{1}$, Paolo Sorzio ${ }^{2}$, \\ ${ }^{1,2}$ University of Trieste, Italy
}

\begin{abstract}
The child-centred approach refers to the specific competencies that practitioners develop, in order to promote children's participation, initiative, exploration and reflection in meaningful activities for an extended period of time. It is considered a pivotal experience to promote children's well-being and learning and it is an index of the quality in the educational services. However, the meanings associated to the "child-centred education" are often contradictory and its presuppositions are seldom stated explicitly.

This contribution presents an analysis of the evaluation offered by a group of students that attended an e-learning training course, concerning the promotion of child-centered practice in early childhood education services, within a European project (Erasmus + 2017-1-UK01KA201-036798). In particular, it was decided to promote some professional skill related to documentation, considered an essential professional skills in the socio-constructivist perspective. However, the analysis of the students" answers gives evidence that a "romantic" approach is quite strong in some initial conceptions of educational approach and the "developmentalist" and the "socio-constructivist" perspectives are not straightforwardly present in the beliefs of future educators. These results show that centrality of the child can be supported by the on-line courses, although it is necessary to present an initial framework that introduces a general orientation to interpret the material presented and to introduce changes in professional practice.
\end{abstract}

Key-words: Child-Centered Education; Documentation; E-learning; Initial Teacher Education; Socio-constructivist Perspective 


\section{LENAEDULATIIN \\ 27-29 March, 2020 \\ Oxford, United Kingdom}

\section{Introduction}

Early childhood education and care (ECEC) is recognized as a long-term strategy to provide the initial foundations of the cognitive and emotional development for all children. In particular, the quality of educational services seems to provide long-term positive effects in the academic success and well-being of potentially at-risk individuals (McCoy et al. 2017).

The European Commission (2018) has identified the importance of education, both initial and in service, of educators as an essential dimension to guarantee the quality of early childhood education services.

\section{The Child-centred education}

The Child-centred education is an approach that has acquired several practical interpretations in its history (Chung and Walsh, 2000).

The "romantic" concept, developed by Fröbel (2001; original 1840) elaborates the idea of childhood as an age tending towards harmony between the Child and Nature; the adult has the task of "fertilizing" the environment, to encourage the development of childhood potential, which manifests itself through play. The implicit presuppositions of the approach consider the child as experiencing the world according to a specific stage of development, as being at the centre of the adults' world and in need of care and support.

The "developmentalist concept" is an alternative vision of the child-centred education, mainly promoted by legislative acts and educational institutions (for a critical analysis: Dahlberg \& Moss, 2005; Fuller, 2007). The central tenet of this approach concerns the role of the child's personal interests and skills in exploring the environment and in self-regulated learning. Attention is paid to the activities that best support the learning of geometric figures, the recognition and reproduction of written letters and numbers and the learning of numbers. In this conception, the more sophisticated abilities such as metacognition and peer collaboration are learned after the basic skills (recognition, reproduction and simple problem-solving activities).

The "socio-constructivist perspective" emerges from the practical elaboration of the Reggio Emilia Schools in Italy, complemented by Bruner's theory.

The idea of the socio-constructivist approach to child-centred educational practice is that the characteristics of the setting, the organization of the educational activities and the patterns of communication (the 'social' aspects) have an impact upon the children's participation and opportunities for learning (the 'construction' of mental schemes). According to the approach, the dialogue among peers and with adults that promotes sustained engagement in exploration, in sharing ideas and responsibilities creates the social conditions that support the children's development of symbolic expressions, democratic attitudes and personal agency.

In this perspective, the adults take on new and sophisticated roles in designing, documenting, organizing educational activities that support participation and promotion of self-reflection and metacognition of children (Bruner, 1978; Hendy and Whitebread, 2000). As a consequence, a broad set of competencies are required to adults, in order to establish and maintain the effective learning environments that promote children's learning; the initial 
teacher education at the University level should address a wide range of concepts and strategies, which are part of the socio-constructivist perspective in child-centred education.

Documentation is a pivotal part of the child-centred approach and it consists in a system of symbolic artefacts intended to communicate some relevant aspects of the children's development and experiences. However, its meaning and function differs, in relation to the specific perspective in which this activity is embedded; documentation is selective in the events, processes and outcomes that are considered relevant to highlight the children's learning. As a consequence, each approach to child-centred educational practice has developed its own specific documentation methodology: in the Romantic perspective, documentation highlights a memorable event, a moment of friendship, a child's achievement; teachers may use the documentation activity to change something in the environment, to trace each child's experiences and character. In the developmentalist perspective, documentation makes use of more standardised tool, in order to identify each child's development and achievement of given milestones; although there is a consideration for manifold paths to children's growth, school readiness and the early recognition of children's competencies is the focus of this documentation model.

In a socio-constructivist approach, documentation is intended to "make learning visible" (Project Zero, \& Reggio Children (2001), inviting teachers to focus upon individual and cooperative processes of thinking, experimentation and creativity that all the children enact when in stimulating environments and motivating activities. As a consequence, documentation requires a more subtle focus of observation, that is, the process of children's design, hypothesis testing, revision, sharing of ideas and realization. Documentation emerges as a narrative of each child's active engagement in a situation, her/his development of competencies to pursue a personal or an intersubjective goal (Carr, \& Lee, 2012). In this perspective, the focus of documentation is the process rather than the achievement.

The Child Centred Diversity in Quality Early Childhood Education and Care (2017-1-UK01KA201-036798) project involved partners from Croatia, Denmark, Italy, United Kingdom, Ireland, with the aim of exploring concepts and practices centred-child and to support quality pedagogy in early childhood education through an e-learning training. The course is aimed to promote a child-centred approach in a socio-constructivist perspective. In particular, it was decided to promote some professional skills related to documentation, as an essential component in the socio-constructivist perspective.

In this contribution we present an overview of the design and implementation of the course on documentation, and of the results obtained through an online survey administered to the Italian students that attended the training.

Given the relevance of the "socio-constructivist perspective" in ECEC, we have inquired the university students' initial conceptions, in order to understand the impact of the online course about documentation on the initial conceptions of the students. 


\section{LINAEDULATION \\ 27-29 March, 2020 \\ Oxford, United Kingdom}

\section{Method}

\subsection{Subjects}

In total 56 italian students attended the on line course; all students are female and a very large group is 20-30 year-old $(53,68 \%)$. All students were attending a BA degree as the initial education of the ECEC workforce.

\subsection{The e-learning training}

The general course consists in three separate modules, translated into different languages, available as an open-access resource, on the site of the project's leading university (https://open.plymouth.ac.uk/login/index.php). The three modules are: documentation, embodiment, narrativity. Each module is divided into five training sessions, each oriented to introduce a specific aspect, through written texts, videos, materials and tools used in educational practices. Trainees have the opportunity to reflect on the relevance of the aspects covered in the practice, both by using the observational and writing tools proposed in each module, and through proposals for personal reflection regarding some aspects of their professional practice.

Each module is aimed at deepening a component of "child-centred" pedagogy and at promoting a change in the educational practices.

The "documentation" module invites the participants to reflect on the different possible formats of documentation (as public displays, multimedia texts, books) and the educational meaning in selecting a relevant focus of attention. Documentation is the construction of material artefacts (as photos, narrative texts, videos; also, an observation grid is a form of documentation). Documentation is not only a personal impression or a record of an event. It has to be transformed into a concrete element, an artefact, that should be shared with colleagues, children and their families. The documentation process should be design initially at the outset of each curricular activity, on the consideration of what is considered important in the child learning.

The documentation process is oriented towards a specific educational aim: it is necessary to have in mind a specific focus of attention in order to recognize a significant event from the information that each educational activity offers.

The project presented materials offered by the partner Coopselios, which is a Cooperative that runs a large number of educational services in Italy and abroad, consistent with the Reggio Emilia Approach; for the specific topics, the students were invited to observe some video-recordings, taken from real contexts, and to recognize some aspects of the childcentered educational approach and of documentation.

The course was developed in different session:

- "Observe" session: photographs that capture some educators in different stages of the documentation are offered. The images show teachers observing children engaged in educational activities, focusing attention on their "doing", rather than on their products. Subsequently, as a professional team, they elaborate a text and discuss it with colleagues;

- In the "Documenting" session, different ways of representing children's activities are introduced: a large display showing both the products and the various stages of the 
process; the richness of the expressive possibilities of children are highlited through videos and photos during their activities, accompanied by their words;

- Session 3 introduces different logics of observation and documentation: narratives (learning stories) and structured observation grids, useful for identifying the children's thinking processes;

- Sessions 4 and 5 show how documentation can become a narrative that accounts for the richness of the expressive and reasoning potential of children, in situations of exploration (respectively in a nursery and in a kindergarten). Finally, is is introduced the use of the artifacts to support communication with families and communities.

In each session, the students are invited to reflect on the relationships between observation and writing, on the relevance of the focus of attention and on the various documentation formats.

\subsection{The Evaluation questionnaire}

An evaluation questionnaire was administered at the end of each module, to evaluate both the appreciation of the course and the subjective evaluation by each participant, regarding any changes in their initial conceptions of the "child-centred" practice.

In this contribution, we present the second part of the questionnaire, which refers to the students' beliefs about some relevant aspects of the Child-centred Practice, explored trough the students' agreement/disagreement on the following questions:

Children learn best when the educator shows the children how to do the activity properly;

Children learn best when they choose their individual learning activities and decide on the length of time they engage with the activity;

Children learn best from group activities;

How important do you feel the elements below are in relation to your work with children?

Children learn best from group activities.

\section{Results}

$54.17 \%$ of students declare that an online training would be effective, and $27.08 \%$ slightly effective for the development of competencies in the Child-centred Practice.

\subsection{Children learn best when the adult shows the children how to do the activity properly}

Students declare a high level of agreement with the statement (stronlgy agree $=30 \%$; agree $=58,70 \%$ ): this surprising result highlights that the child-centred perspective is not an initial conception and therefore its educational and cultural presuppositions should be clearly addressed in the Teacher Initial Education. 
Figure 1: Agreement "Children learn best when the educator shows the children how to do the activity properly"

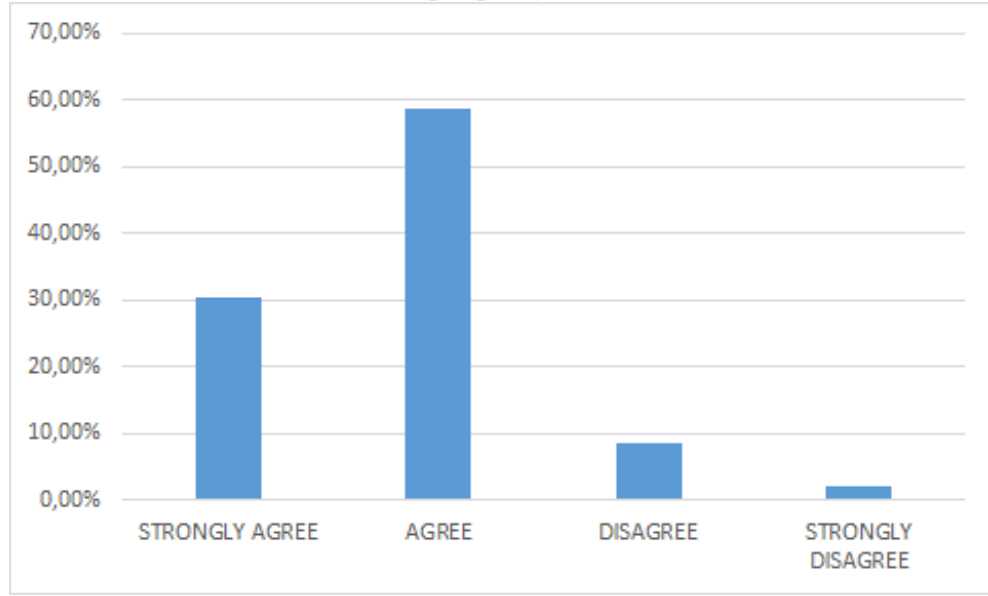

\subsection{Children learn best when they choose their individual learning activities and decide on the length of time they engage with the activity}

Students express a general agreement with this statment (agree $=43,48 \%$ ); however, a significant rate of students $(26,09 \%)$ disagree, suggesting an alignment with an adult-centred perspective. This result may be in contradiction with the one in the former item. However, it may be guessed that it is interpreted as the child-initiated activity may be under the adult's control, or that the play activities are considered recreational in early education and not part and parcel of children's development.

Figure 2: Agreement "Children learn best when they choose their individual learning activities and decide on the length of time they engage with the activity"

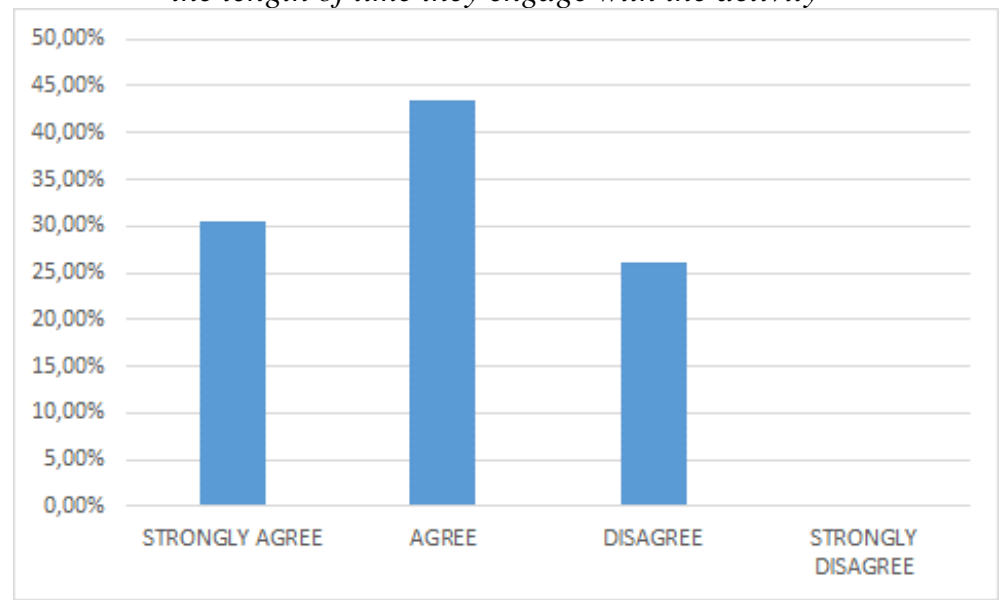

\subsection{Children learn best when educators decide on the themes or topics which children learn best from}

Students show a high level of orientation to an adult-centred approach (strongly agree $=30 \%$, agree $=54,35 \%$ ); It may be related to a traditional model in ECEC, which underlies some 
teaching in initial education and/or to the rigid organization of the settings. This belief may be expressed as the child being at the centre of the adult's world, expressing her/his own desires and interests, but lacking sufficient self-regulation and expression to pursue the intended goals of the activities.

Figure 3: Agreement "Children learn best when educators decide on the themes or topics which children learn

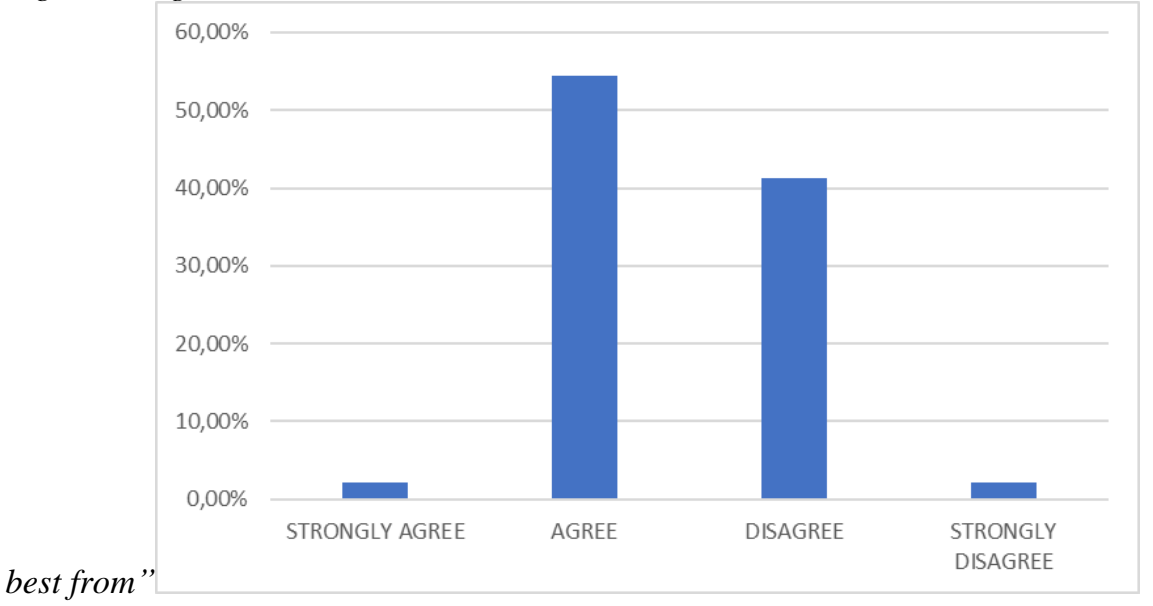

\subsection{Children learn best from group activities}

There is a large agreement with the statement (strongly agree $=36,96 \%$; agree $=54,35 \%$ ). We can assume that group learning may be consistent with the teacher-initiated activities. Working in group may be more acceptable than promoting the child's individual agency.

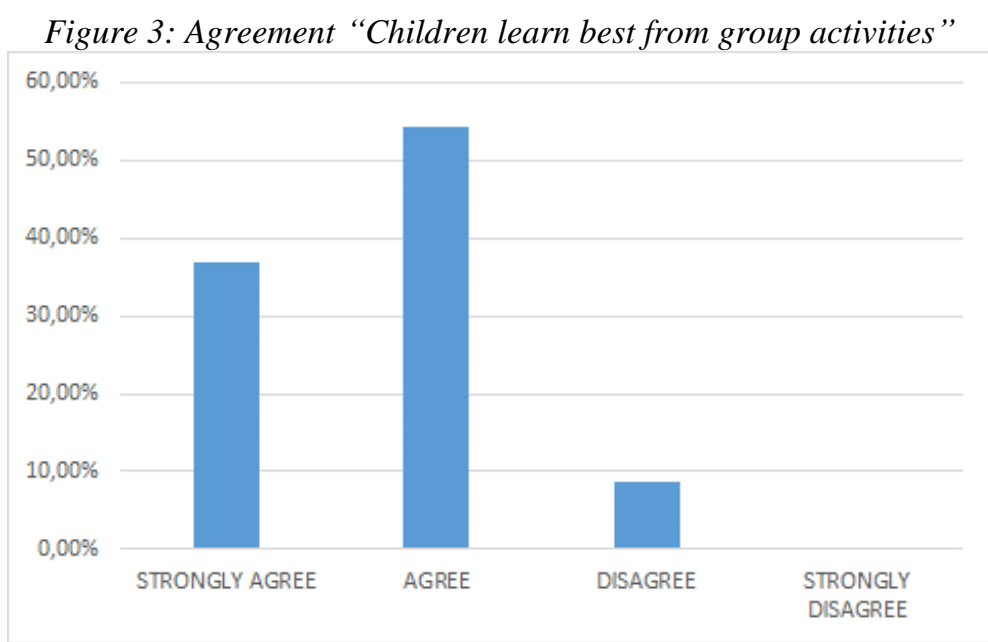




\section{LINAEDULATION \\ 27-29 March, 2020 \\ Oxford, United Kingdom}

\subsection{Discussion}

Our results show that the "traditional" approach is quite strong in some initial conceptions held by university students. The theoretical and educational framework that supports the Child-centred Approach is not straightforwardly present in the initial beliefs of the prospective practitioners; consequently, a specific programme to introduce the presuppositions of the child-centred approach seems useful.

A report based on observing qualified educators work with children in ECEC demonstrated that there were many different roles for an adult, whereby an adult could work directly with children, as a facilitator or as a passive observer (Campbell-Barr et al., 2018). Often, the group dynamics and ECEC practice requires that adults undertake more than role at once. However, for those in their initial training, there is evidence that they are still negotiating their understanding of their own role and how it relates to an educational perspective.

\section{Conclusion}

Although the child-centred approach is commonly assumed as the best educational practice to promote children's learning and well-being, its presuppositions are often contradictory. Promoting a "developmentalist" or a "democratic" approach to child-centredness requires a conceptual change in initial teacher education. The students in our study tend to rely more on a "traditional" vision of the child, as an active subject of her/his play, enjoying the participation in groups and in need of an adult model, in order to learn. This approach has some consequences: documentation is only a residual tool to keep memoires of significant events or feelings, but its role in the design of stimulating environments to promote children's initiative and collaboration in thinking is hardly considered. Promoting a "child-centred perspective" in Initial Teacher Education requires an explicit initial framework that introduces a general orientation about child development, the languages the children use in communicating their thoughts and in working out collaborative activities; the implication of multiple adults' scaffolding strategies that promote children's self-regulation and metacognition, along with the correct procedures.

An online course offers the materials to highlight the relevance of documentation in promoting children's active engagement in their learning, as well as to develop an understanding of the differences among the three perspectives of the "child-centred education". 


\section{References}

[1] Bruner, J. (1978). The role of dialogue in language acquisition, In A. Sinclair, R., J. Jarvelle, \& W. J. M. Levelt (eds.), The Child's Concept of Language. New York: Springer.

[2] Campbell-Barr, V. (2017). "Interpretations of child centred practice in early childhood education and care". Compare, 47, n. 1, pp. 1-17.

[3] Carr, M. \& Lee, W. (2012). Learning Stories. Constructing Learner Identities in Early Education. London: Sage.

[4] Chung, S. \& Walsh, D.J. (2000). Unpacking childcentredness. A history of meanings. Journal of Curriculum Studies, 32, n. 2, pp. 215-234.

[5] Dahlberg, G, \& Moss, P. (2005). Ethics and Politics in Early Childhood Education, London: Routledge;

[6] Fröbel, F.W.A. (2001, original 1840). Friedrich Froebel's Pedagogies of the kindergarten. In K. J. Brehony (Ed.), The origins of nursey education: Friedrich Froebel and the English system (Vol. 1). London: Routledge

[7] Fuller, B. (2007). Standardized Childhood. Palo Alto, CA: Stanford University Press.

[8] Hendy, L. \& Whitebread, D. (2000) Interpretations of independent learning in the Early Years. International Journal Early Years Education, 8, n. 3, pp. 245-52.

[9] McCoy, D., Yoshikawa, H., Ziol-Guest, K., Duncan, G., Schindler, H., Magnuson, K., Yang, R., Koepp, A., Shonkoff, J. (2017). Impacts of Early Childhood Education on medium- and long-term educational outcomes. Educational Researcher, 46, n. 8, pp. 474487.

[10]Project Zero, \& Reggio Children (2001). Making learning visible. Children as individual and group learners. Reggio Emilia, I: Reggio Children Publisher. 